\title{
An in vivo fluorescence method for the continuous in situ estimation of phytoplankton photosynthetic characteristics*
}

\author{
Serge Demers ${ }^{1}$, Jean-Claude Therriault ${ }^{1}$, Louis Legendre ${ }^{2} \&$ Jacques Neveux $^{3}$ \\ ${ }^{1}$ Centre Champlain des Sciences de la Mer, Ministère des Pêches et des Océans B. P. 15500, \\ 901 Cap-Diamant, Québec G1K 7Y7, Canada \\ 2 Département de biologie, Université Laval, Québec G1K 7P4, Canada \\ ${ }^{3}$ Laboratoire Arago, Université Pierre et Marie Curie, F-66650 Banyuls-sur-mer, France
}

\begin{abstract}
This study proposes a simple method to continuously measure, in situ, an in vivo fluorescence characteristic of a natural phytoplankton population, using 2 flow-through fluorometers and a strong light source. By this method, phytoplankton fluorescence before $\left(F_{B}\right)$ and after $\left(F_{A}\right)$ strong illumination $\left(2250 \mu\right.$ Ein $\left.\mathrm{m}^{-2} \mathrm{~s}^{-1}\right)$ was measured simultaneously with parameters of the photosynthesis vs irradiance curves. Data from 3 depths in the mixed layer, at 3 stations in the St. Lawrence Estuary, showed a strong relation between the ratio $F_{A} / F_{B}$ and the photosynthetic parameters $\alpha^{B}, P_{\max }^{B} I_{k}$ and $I_{m}$. The relation was particularly good with $I_{k}$ and $I_{m}, 2$ possible indices of physiological adaptation. These results suggest that the ratio $\mathrm{F}_{\mathrm{A}} / \mathrm{F}_{\mathrm{B}}$ can be used as an instantaneous in vivo index of photosynthetic characteristics. This simple measurement might prove useful for continuous spatio-temporal investigations of phytoplankton responses to their light environment in the water column.
\end{abstract}

\section{INTRODUCTION}

Continuous measurements of in vivo fluorescence, as an estimator of in situ chlorophyll a (Lorenzen 1966), have resulted in a new understanding of phytoplankton patchiness and dynamics (see Legendre \& Demers 1984). On the other hand, the photosynthetic characteristics of phytoplankton are still largely determined from discrete samples, although Massol \& Ballester (1976) have used the Technicon Auto-Analyser to sample continuously small volumes of water, to which ${ }^{14} \mathrm{C}$ was added in order to continuously measure primary production. Alternatively, a number of studies have tried to relate in vivo fluorescence, with and without the photosynthetic inhibitor 3-(3,4-dichlorophenyl)1,1-dimethyl urea (DCMU), to the photosynthetic activity of phytoplankton (Samuelsson \& Oquist 1977, Samuelsson et al. 1978, Cullen \& Renger 1979, Roy \& Legendre 1979, 1980, Vincent 1980, Neveux 1982, Bates \& Platt 1984), but field results were in general not really satisfactory (Harris 1980a). Fluorescence,

- Contribution to the program of GIROQ (Groupe interuniversitaire de recherches océanographiques du Québec) however, still remains the only continuous variable that can be easily and routinely measured in situ on a phytoplankton population. Caution should be exercised in the interpretation of in vivo fluorescence measurements, since several studies have indicated a large range of variation of the fluorescence yield per unit chlorophyll $a$, in time and space (Blasco 1973, Kiefer 1973a, b, Loftus \& Seliger 1975, Heaney 1978, Harris $1980 \mathrm{~b}$ ) and in relation to the recent history of the phytoplankton cells (see review by Prézelin 1981). It has been suggested that these changes in the fluorescence yield could be linked to the photosynthetic activity of phytoplankton (Butler 1977, see also review by Prézelin 1981).

Using fluorescence induction curves, which measure the time-varying fluorescence signal following the onset of constant illumination, is another way to obtain information on some aspects of the photosynthetic activity of phytoplankton. It is assumed that each phase of the fluorescence kinetics corresponds to specific changes in the photosynthetic apparatus (Papageorgiou 1975, Lavorel \& Etienne 1977, Prézelin 1981). Two phases are usually recognized in the fluorescence induction curves (the Kautsky effect). The 
fast phase (within the first second of exposure to bright light) is characterized by a rapid rise in fluorescence and is mainly associated with photochemical changes in photosystem II (Papageorgiou 1975). The slow phase does not appear to be directly linked to the photochemistry of photosynthesis and more likely reflects the distribution of excitation energy between the 2 photosystems (cf. Prézelin 1981). Following the fast initial rise upon illumination, the decrease of fluorescence, sometimes below the initial fluorescence level $F_{0}$ (Loftus \& Seliger 1975), appears to be strongly influenced by endogeneous and environmental conditions, such as preillumination adaptations (Lavorel \& Etienne 1977). For phytoplankton cultures, Neveux \& Jupin (1981) have shown variations in the fluorescence kinetics during the slow phase which were related to taxonomic differences, the light intensity of the excitation beam, and the physiological state of the cells as affected by age or various pollutants. Such variations have also been demonstrated for natural phytoplankton (Vincent 1979, Neveux 1982) in relation to the pretreatment with different light intensities. For the fast phase, Bates \& Platt (1984) found a strong positive correlation between the photosynthetic capacity and the area above the fluorescence induction curve after addition of DCMU, for two species of phytoplankton in batch cultures. These results suggest that it might be possible to relate some characteristics of the fluorescence induction curves to precisely defined changes in the photosynthetic activity of the cells. However, a major problem with fluorescence kinetics, as far as field studies are concerned, is that continuous measurements cannot be made since fluorescence kinetics must be conducted on discrete samples.

\section{LABORATORY MEASUREMENTS}

In this paper, we propose a simple procedure to measure continuously, in situ, 1 point on a fluorescence induction curve. This simple method is based on the assumption that changes in the fluorescence induction curves reflect differences in the previous environmental history of a phytoplankton population (see above) and that cells with a similar light history will show similar fluorescence induction curves when excited with the same light energy. We postulated that discrete values of a fluorescence induction curve could be obtained simply by measuring the in vivo fluorescence with an ordinary fluorometer, after exposure of the cells to a constant bright light source for different periods of time (say between 2 and $60 \mathrm{~s}$ ). Plotting these values as a function of exposure time would then give the slow phase of the fluorescence induction curve. This can be achieved by measuring the in vivo fluorescence (using a Turner Designs instrument or another ordinary flow-through fluorometer) of samples pumped through different lengths of transparent tubing exposed to a strong light source (2000 W halogen tungsten lamp). The same result can also be achieved by changing the flow rate, while keeping constant the length of the transparent tubing. Since the weak excitation beam (actinic light) of the fluorometer was not reported to cause induction phenomena (Harris 1980b), we thought we could use the fluorescence before exposure to strong light $\left(\mathrm{F}_{\mathrm{B}}\right)$ as a reference, to look for changes in fluorescence following exposure to a $2250 \mu$ Ein $\mathrm{m}^{-2} \mathrm{~s}^{-1}$ actinic light. However, recent work by Sweet $\&$ Guinasso (1984) has shown an effect of flow rate on in vivo fluorescence, suggesting that the actinic light of the Turner Designs fluorometer might be strong enough to cause fluorescence induction. To test this hypothesis, we carried out laboratory experiments on 2 different batch cultures of Phaeodactylum tricornutum, grown under 2 different light intensities $(65$ and $485 \mu$ Ein $\mathrm{m}^{-2} \mathrm{~s}^{-1}$ ), in order to determine the effect of flow rate on the initial fluorescence $\left(F_{B}\right)$. Fig. 1 clearly shows variations of fluorescence depending on the residence time in the fluorometer cell (determined as in Sweet \& Guinasso 1984). It appears, however, that the light pretreatment has no effect on $F_{B}$ and that a plateau of fluorescence is reached for residence times greater than about $0.2 \mathrm{~s}$ (or flow rates less than about $3000 \mathrm{ml} \mathrm{s}^{-1}$ ), such that $F_{B}$ can be considered as constant under these conditions. Other experiments carried out on cultures of Dunaliella tertiolecta with the same approach gave essentially the same results.

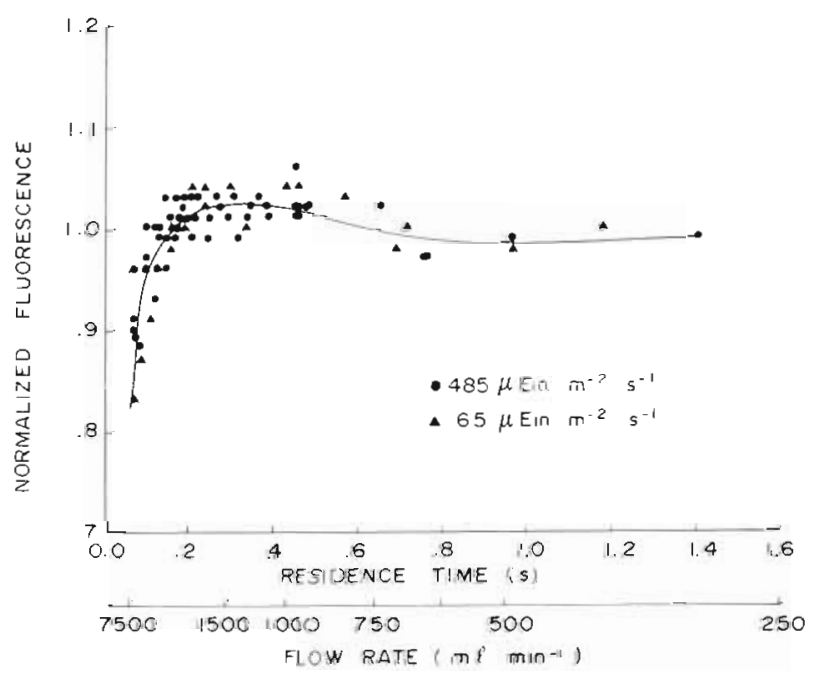

Fig. 1. Phaeodactylum tricornutum. Normalized (to the value of the plateau, at residence time $\geqslant 0.6 \mathrm{~s}$ ) fluorescence of cultures grown at 2 constant light intensities ( 65 and $485 \mu$ Ein $\mathrm{m}^{-2} \mathrm{~s}^{-1}$ ) as a function of residence time in the illuminated portion of the fluorometer. Determined as in Sweet \& Guinasso (1984) 
Therefore, our results seem to confirm the fact that the actinic light of the Turner Designs fluorometer is strong enough to cause fluorescence induction phenomena, but they also show that with appropriate time of exposure or flow rate, $F_{B}$ can be used as a basic reference for fluorescence.

Using our Phaeodactylum tricornutum cultures, we made further measurements of fluorescence as a function of the time of exposure to bright light as described above. The results obtained (Fig. 2) indicate variations in the standardized fluorescence (fluorescence after

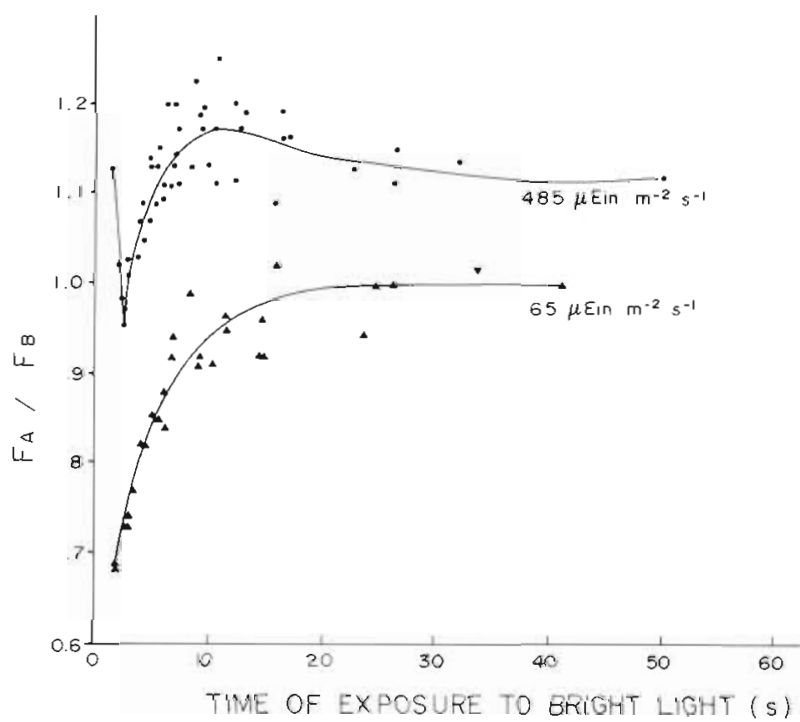

Fig. 2. Phaeodactylum tricornutum. Variations in the fluorescence ratio (fluorescence after exposure to bright light/ fluorescence prior to exposure) of cultures grown at 2 constant light intensities ( 65 and $485 \mu \mathrm{Ein} \mathrm{m}^{-2} \mathrm{~s}^{-1}$ ), as a function of the time of exposure to bright light $\left(2250 \mu\right.$ Ein $\left.\mathrm{m}^{-2} \mathrm{~s}^{-1}\right)$

exposure to bright light, $F_{A}$, divided by that prior to exposure, $F_{B}$ ), as a function of the time of exposure to bright light. The curves are different depending on the light intensity at which the cultures were grown. The changes in the fluorescence ratio with time (Fig. 2) closely resemble the fluorescence induction curves without DCMU addition that were obtained by Neveux \& Jupin (1981) for various phytoplankton cultures and natural populations (see also our Fig. 5). Whether the curves in Fig. 2 are genuine fluorescence induction curves or not may be debatable on theoretical grounds. However, it will be shown below that field data (Fig. 5) do link our fluorescence ratio to fluorescence induction. One characteristic of the curves in Fig. 2 is that after the initial increase and decrease during the fast phase (which was partially missed in our experiments) and the subsequent increase during the slow phase, a plateau of fluorescence is reached. A number of studies have indicated that the relative level of this plateau is strongly dependent on the previous light history of the cells (Mohanty \& Govindjee 1974, Lichtenthaler 1981, Govindjee et al. 1979, Vincent 1979, 1980, Neveux \& Jupin 1981). It was thought, therefore, that the level of the plateau could be related in some way to light adaptation. The purpose of our study was not to investigate the physiological basis of this relation, but rather to investigate whether a relatively simple continuous in vivo measurement could be related to the usual indices of photosynthetic performance. If so, these results would call for further physiological studies, to relate in vivo fluorescence more accurately to photosynthetic changes.

\section{FIELD MEASUREMENTS}

To test this hypothesis, measurements of photosynthesis versus irradiance, fluorescence kinetics and fluorescence ratios were carried out at 3 stations in the St. Lawrence Estuary. These stations were chosen for their different physical, chemical and biological characteristics (see Table 1).

Each station was occupied for 30 consecutive h. Every half-hour, an automatic profiling system recorded temperature, salinity (Guildline CTD probe) and underwater light intensities (Biospherical Instruments $4 \pi$ collector). Every second hour, water was sampled (Niskin bottles) at 4 depths, for the measurement of chlorophyll a concentration, photosynthesis versus irradiance and fluorescence induction. Chlorophyll a concentrations were determined on acetone-extracted Whatman GF/C filters $(250 \mathrm{ml}$ filtrations) using the fluorometric method of Yentsch \& Menzel (1963). Photosynthesis versus irradiance measurements were made on water samples from the first 3 depths, using the photosynthetron (Lewis \& Smith 1983). Parameters $\alpha^{B}, P_{\max }^{B}, I_{k}$ and $I_{m}$ of the photosynthesis versus irradiance curves were estimated using the model of Platt et al. (1980). These parameters were calculated using ${ }^{14} \mathrm{C}$ uptake values standardized per unit chlorophyll a (B). Fluorescence induction measurements were carried out using the second version of the fluorometric equipment described by Neveux (1982).

To monitor the plateau of the fluorescence kinetics continuously, we used in the field a technique similar to the one described above for laboratory measurements, but this time with 2 fluorometers. Water was first pumped through a Turner Designs fluorometer (flow rate set at $3000 \mathrm{ml} \mathrm{min}^{-1}$ for technical reasons) in order to measure the initial fluorescence $\left(F_{B}\right)$, and then circulated for $16 \mathrm{~s}$ in a transparent tube exposed to bright light $\left(2250 \mu\right.$ Ein $\left.\mathrm{m}^{-2} \mathrm{~s}^{-1}\right)$, before measuring the fluorescence $\left(\mathrm{F}_{\mathrm{A}}\right)$ with a second fluorometer which was 
Table 1. Location, depth and sampling dates of the 3 sampling stations, $\bar{Z}_{\mathrm{m}}$ and $\bar{Z}_{\mathrm{e}}$ : mean mixed layer and euphotic zone depths, respectively; $\overline{\mathrm{I}}_{0}$ : mean incident light radiation; $\langle\overline{\mathrm{I}}\rangle$ : average of mean light intensity in mixed layer. Values of temperature $(\overline{\mathrm{T}})$, salinity $(\overline{\mathrm{S}})$, chlorophyll a $(\overline{\mathrm{Chl}})$ and nitrate $\left(\overline{\mathrm{NO}_{3}}\right)$ are also averaged over the mixed layer for the duration of the sampling period $(30 \mathrm{~h})$ at each station

\begin{tabular}{|c|c|c|c|}
\hline & Station 2 & Station 4 & Station 5 \\
\hline Location & $\begin{array}{l}69^{\circ} 05.5^{\prime} \mathrm{W} \\
48^{\circ} 32.2^{\prime} \mathrm{N}\end{array}$ & $\begin{array}{l}68^{\circ} 05.0^{\prime} \mathrm{W} \\
48^{\circ} 44.3^{\prime} \mathrm{N}\end{array}$ & $\begin{array}{l}67^{\circ} 17.3^{\prime} \mathrm{W} \\
48^{\circ} 57.3^{\prime} \mathrm{N}\end{array}$ \\
\hline Sampling date & 6 Sep 82 & $2 \operatorname{Sep} 82$ & 30 Aug 82 \\
\hline Station depth (m) & 68 & 85 & 100 \\
\hline$\overline{\mathrm{I}}_{0}\left(\mu \operatorname{Ein} \mathrm{m}^{-2} \mathrm{~s}^{-1}\right)$ & 1594 & 398 & 1527 \\
\hline$\overline{\mathrm{Z}}_{\mathrm{m}}(\mathrm{m})$ & 8.7 & 5.1 & 40.0 \\
\hline $\bar{Z}_{e}(\mathrm{~m})$ & 5.1 & 5.9 & 5.0 \\
\hline$<\overline{\mathrm{I}}>\left(\mu \operatorname{Ein} \mathrm{m}^{-2} \mathrm{~s}^{-1}\right)$ & 405 & 88 & 42 \\
\hline$\overline{\mathrm{T}}\left({ }^{\circ} \mathrm{C}\right)$ & 6.8 & 7.4 & 6.6 \\
\hline $\bar{S}(\%)$ & 28.42 & 28.10 & 29.47 \\
\hline$\overline{\mathrm{Chla}}\left(\mathrm{mg} \mathrm{m}^{-3}\right)$ & 14.7 & 11.3 & 11.0 \\
\hline$\overline{\mathrm{NO}_{3}}\left(\mathrm{mg}\right.$-at $\left.\mathrm{m}^{-3}\right)$ & 3.6 & 5.2 & 2.6 \\
\hline
\end{tabular}

calibrated with the first fluorometer. It was expected that the ratio of fluorescence after $\left(F_{A}\right)$ and before $\left(F_{B}\right)$ exposure to the bright light $\left(F_{A} / F_{B}\right)$ would be linked to some photosynthetic characteristics of the phytoplankton population.

\section{FIELD RESULTS AND DISCUSSION}

Table $2 a$ shows highly significant $(p \leqslant 0.01)$ linear correlations between the fluorescence before $\left(F_{B}\right)$ and after $\left(\mathrm{F}_{\mathrm{A}}\right)$ exposure to bright light, and chlorophyll $a$ concentrations at the 3 stations. However, when partial correlation coefficients are computed (Table 2b), $F_{A}$ and chlorophyll a do not remain significantly correlated $(\mathrm{p} \geqslant 0.05)$ when controlling for $\mathrm{F}_{\mathrm{B}}$. According to Legendre \& Legendre (1983), the causal model that can account for the correlations in Table 2 is the interven-

Table 2. (a) Coefficients of linear correlation between fluorescence before $\left(\mathrm{F}_{\mathrm{B}}\right)$ and after $\left(\mathrm{F}_{\mathrm{A}}\right)$ exposure to bright light, and chlorophyll $a$ at the 3 stations. (b) Partial correlation coefficients between the 3 variables

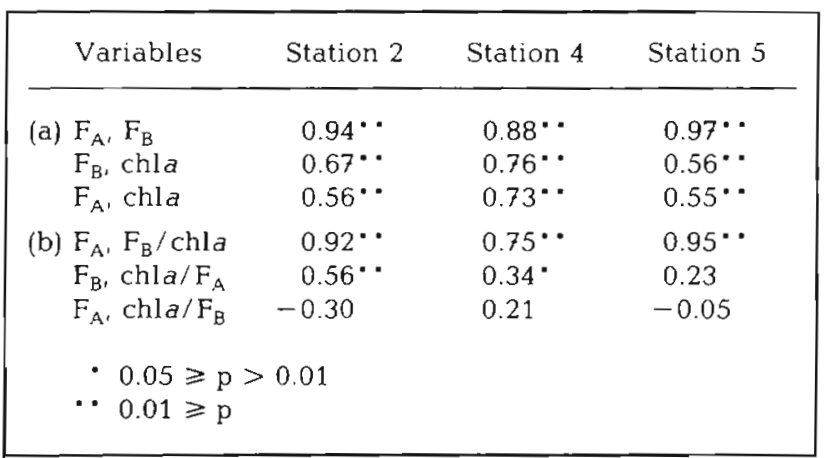

ing sequence, where chlorophyll a (primary variable) influences $F_{B}$ (secondary variable) which in turn influences $F_{A}$ (dependent variable). Therefore, the ratio $F_{A}$ ' $F_{B}$ is independent of biomass and can be used to estimate a characteristic of the fluorescence induction kinetics.

The temporal changes in $\mathrm{F}_{\mathrm{A}} / \mathrm{F}_{\mathrm{B}}$ show strong diurnal variations at all depths for the 3 stations. This ratio, however, does not seem to depend on the relative mean light intensity in the mixed layer (Fig. 3). It is therefore of great interest to test if these diurnal variations in $\mathrm{F}_{\mathrm{A}} / \mathrm{F}_{\mathrm{B}}$ are related to the photosynthetic parameters (normalized to chlorophyll a). Significant correlations are observed between $F_{A} / F_{B}$ and all the measured photosynthetic parameters (Table 3). Of particular interest, however, is the fact that the correlations are especially good with the 2 derived parameters $I_{k}$ and $I_{m}$, which have often been used to characterize the physiological adaptation of phytoplankton to the light environment in the water column (e.g. Talling 1957 ,

Table 3. Coefficients of linear correlation between the ratio $\mathrm{F}_{\mathrm{A}} / \mathrm{F}_{\mathrm{B}}$ and the photosynthetic parameters $\alpha^{\mathrm{B}}, \mathrm{P}_{\max }^{\mathrm{B}}, \mathrm{I}_{\mathrm{k}}$ and $\mathrm{I}_{\mathrm{m}}$ (Platt et al. 1980), at the 3 sampling stations

\begin{tabular}{|c|c|c|c|}
\hline Variables & Station 2 & Station 4 & Station 5 \\
\hline $\mathrm{F}_{\mathrm{A}} / \mathrm{F}_{\mathrm{B}}, \mathrm{P}_{\text {max }}^{\mathrm{B}}$ & $-0.43^{\cdots}$ & $-0.64 \cdots$ & $-0.35^{\circ}$ \\
\hline$F_{\mathrm{A}^{\prime}} F_{\mathrm{B}}, \alpha^{\mathrm{B}}$ & $0.44^{\circ}$ & $0.42 \cdots$ & $0.43 \cdots$ \\
\hline$F_{A} / F_{B}, I_{k}$ & $-0.67^{\cdots}$ & $-0.68^{\cdots}$ & $-0.66^{\cdots}$ \\
\hline$F_{A^{\prime}} F_{B}, I_{m}$ & $-0.61 \cdots$ & $-0.59^{\cdots}$ & $-0.67 \cdots$ \\
\hline \multicolumn{4}{|c|}{$\cdot 0.05 \geqslant p>0.01$} \\
\hline
\end{tabular}




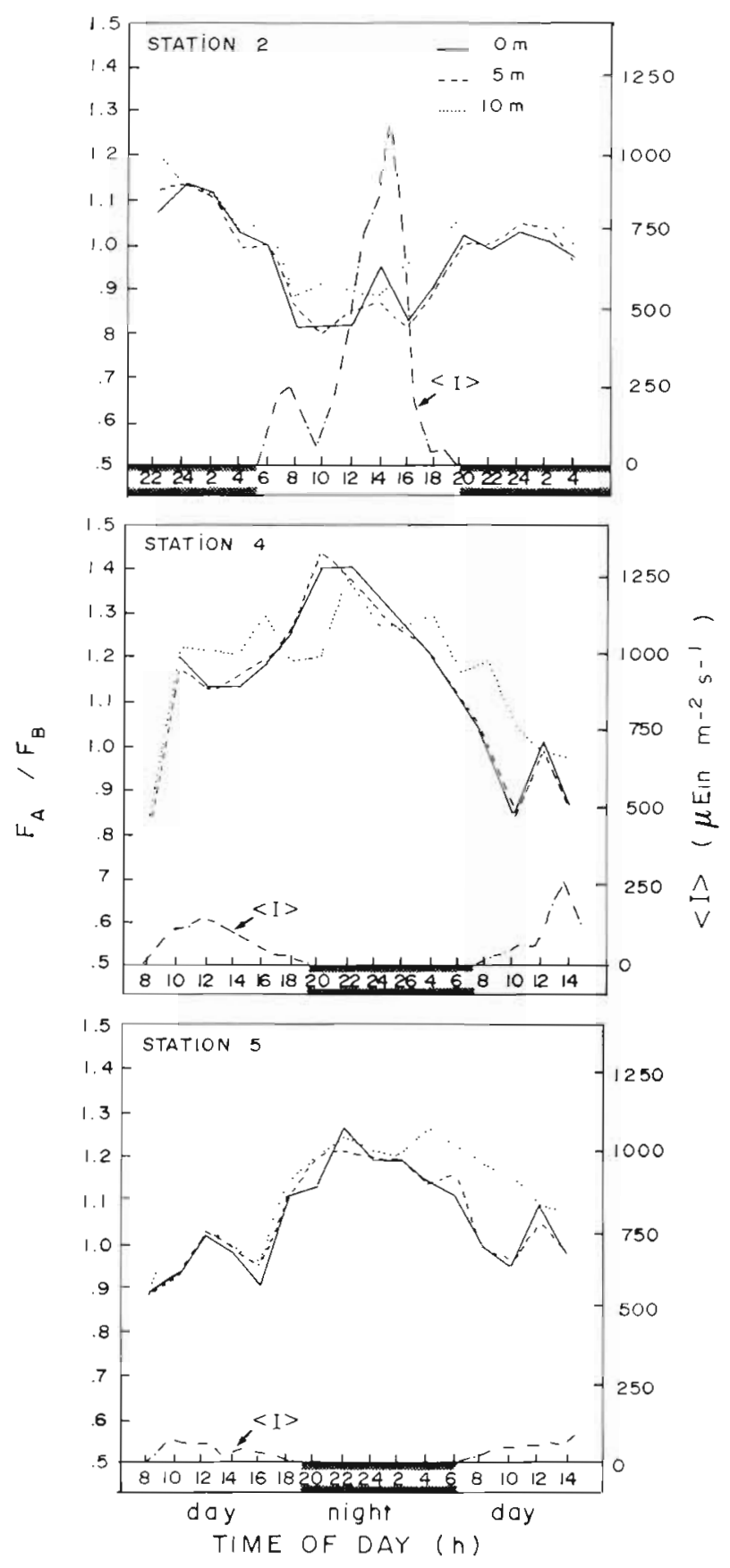

Fig. 3. Diurnal variations of the fluorescence ratio $F_{A} / F_{B}$ and the mean light intensity in the mixed layer $(<\overline{\mathrm{I}}\rangle)$ at the 3 sampling stations

Yentsch \& Lee 1966, Platt et al. 1980, Platt et al. 1982).

Our measurements of fluorescence induction kinetics at the 3 stations indicated diurnal variations as well as variations with depth. Typical examples are shown in Fig. 4 . The ratio $F_{A} / F_{B}$ was compared with the fluorescence values from the kinetics induction curves after $16 \mathrm{~s}$ of illumination $\left(\mathrm{F}_{16} / \mathrm{F}_{0}\right)$ and highly significant $(p \leqslant 0.01)$ correlations were obtained (Fig. 5). The rela-

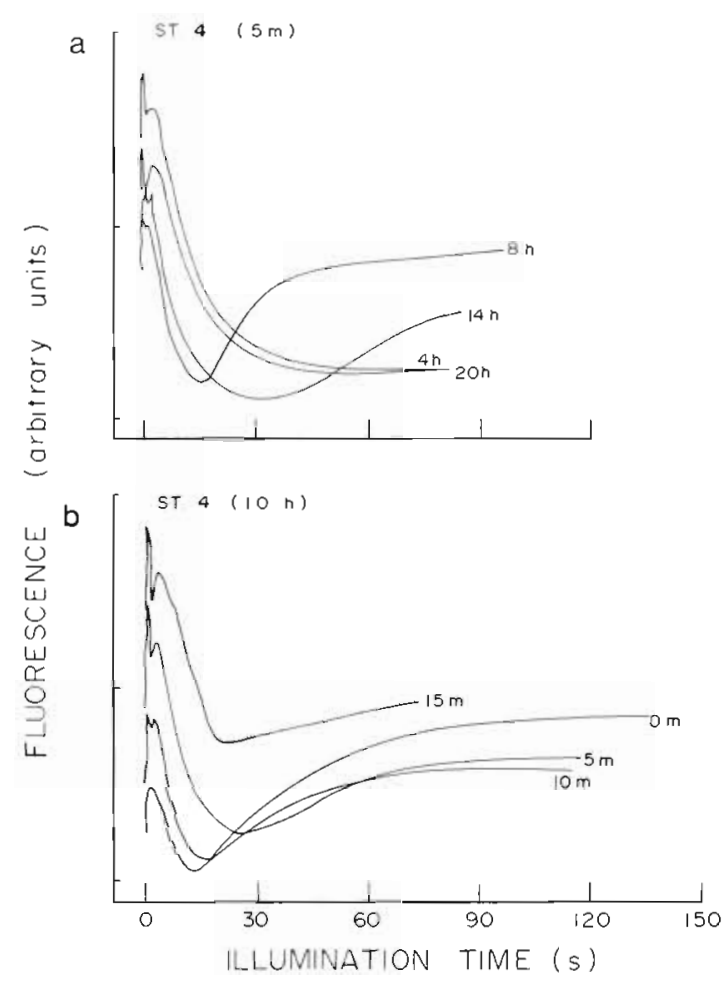

Fig. 4. Typical variations of the fluorescence induction kinetics with time of the day (a) and depth (b) at Station 4

tively high scatter in the regression plots was largely due to 2 factors: the sampling errors $\left(\mathrm{F}_{\mathrm{A}} / \mathrm{F}_{0}\right.$ measured from pumped samples and $F_{16} / F_{0}$ measured from Niskin bottle samples) and the analytical errors, which are uncorrelated for the 2 sets of measurements. This gives support to our above interpretation of Fig. 2, in terms of fluorescence induction curves. Even if this interpretation is not entirely correct on physiological grounds, it is clear that our fluorescence ratio $\left(\mathrm{F}_{\mathrm{A}} / \mathrm{F}_{\mathrm{B}}\right)$ has a meaning similar to that of fluorescence induction after $16 \mathrm{~s}$ $\left(\mathrm{F}_{16} / \mathrm{F}_{0}\right)$. By changing the illumination time, it may be possible to determine various physiological characteristics that might be reflected in the fluorescence induction curves.

Methods used to measure phytoplankton photosynthetic parameters require incubation times varying between $20 \mathrm{~min}$ (photosynthetron: Lewis \& Smith 1983 ) and $4 h$, so it is possible that phytoplankton cells undergo physiological changes during the incubation. The instantaneous in situ estimation of the fluorescence ratio $\mathrm{F}_{\mathrm{A}} / \mathrm{F}_{\mathrm{B}}$ eliminates this source of error and allows the continuous in situ measurement of photosynthetic characteristics on either the vertical or the horizontal axis. Since it is well known that vertical mixing is an important parameter affecting phytoplankton photosynthesis (Falkowski 1983), the possibility of measuring a photosynthetic response on a 


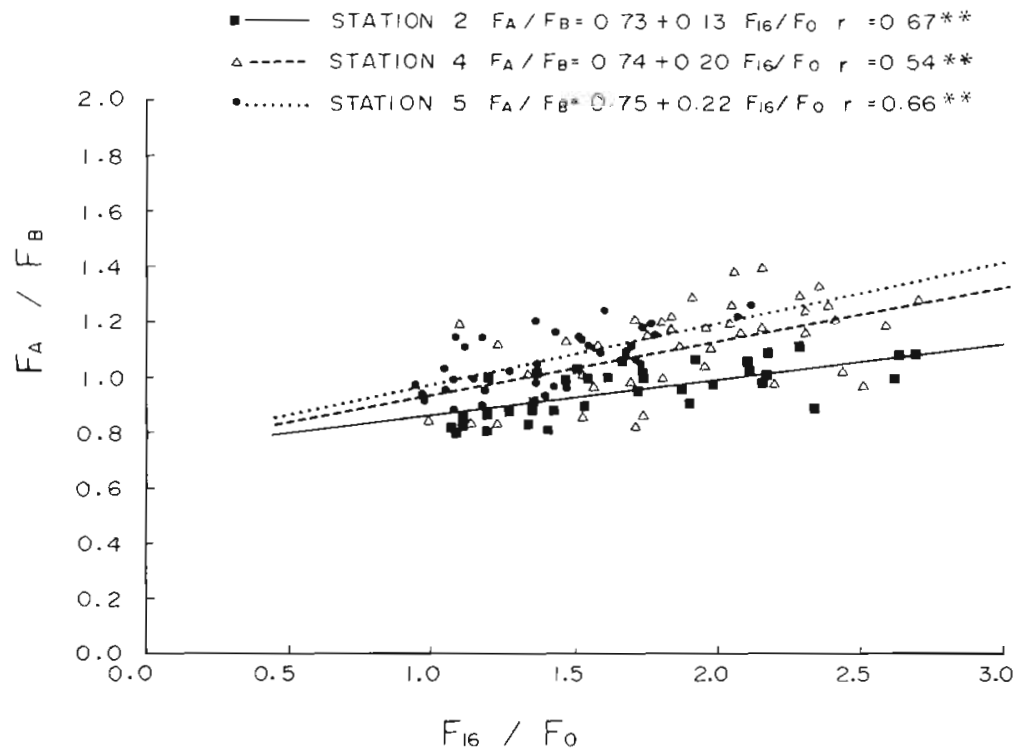

Fig. 5. Linear regressions of the fluorescence ratio $F_{A} / F_{B}$ and the ratio of the initial fluorescence values $\left(F_{0}\right)$ from the kinetics induction curves to the fluorescence value recorded after $16 \mathrm{~s}$ of illumination $\left(\mathrm{F}_{16}\right) \cdots p \leqslant 0.01$ continuous basis may prove to be valuable in deriving models of vertical mixing such as the one proposed by Lewis et al. (1984).

Acknowledgements. This study was supported by the Champlain Centre for Marine Sciences and Surveys (Department of Fisheries and Oceans, Canada), by the Groupe interuniversitaire de recherches océanographiques du Québec (GIROQ), by the Fonds FCAC and the Natural Sciences and Engineering Research Council of Canada, and by NSERCC grants to L. L. J.N. participated in the cruise in the St. Lawrence Estuary thanks to the France-Québec and France-Canada scientific exchange programs, which also financed subsequent travel to France for the other authors. We thank C. S. Yentsch for his most useful suggestions, as well as R. Barlow, S. S. Bates, J. J. Cullen, P. G. Falkowski, $M$. R. Lewis and 1 other anonymous reviewer for their constructive criticisms on the manuscript.

\section{LTTERATURE CITED}

Bates, S. S., Platt, T. (1984). Fluorescence induction as a measure of photosynthetic capacity in marine phytoplankton: response of Thalassiosira pseudonana (Bacillariophyceae) and Dunaliella tertiolecta (Chlorophyceae). Mar. Ecol. Prog. Ser. 18: 67-77

Blasco, D. (1973). Estudio de la variaciones de la relación fluorescencia in vivo/clorofila $a$, y su aplicacion en oceanografía. Influencia de la limitación de differentes nutrients, efecto del dia y noche $y$ dependencia de la especia estudias. Investigación pesq. 37: 533-556 (in Spanish)

Butler, W. L. (1977), Chlorophyll fluorescence: a probe for electron transfer and energy transfer. In: Trebst, A., Avron, M. (ed.) Photosynthetic electron transport and photophosphorylation. Springer-Verlag, Berlin, p. 149-167

Cullen, J. J., Renger, E. (1979). Continuous measurement of the physiological state of natural fluorescence response. Mar. Biol. 53: 13-20
Falkowski, P. G. (1983). Light-shade adaptation and vertical mixing of marine phytoplankton: A comparative study. J. mar. Res. 41: 215-237

Govindjee, Wong, D., Prézelin, B. B., Sweeney, B. M. (1979). Chlorophyll a fluorescence of Gonyaulax polyedra grown on a light-dark cycle and after transfer to constant light. Photochem. Photobiol. 30: 405-411

Harris, G. P. (1980a). Temporal and spatial scales in phytoplankton ecology. Mechanisms, methods, models, and management. Can. J. Fish. Aquat. Sci. 37: 877-900

Harris, G.P. (1980b). The relationship between chlorophyll a fluorescence, diffuse attenuation changes and photosynthesis in natural phytoplankton populations. J. Plankton Res. 2: 109-127

Heaney, S. I. (1978). Some observations on the use of the in vivo fluorescence technique to determine chlorophyll $a$ in natural populations and cultures of freshwater phytoplankton. Freshwat. Biol. 8: 115-126

Kiefer, D. A. (1973a). Chlorophyll a fluorescence in marine centric diatoms: responses of chloroplasts to light and nutrient stress. Mar. Biol. 23: 39-46

Kiefer, D. A. (1973b). Fluorescence properties of natural phytoplankton populations. Mar. Biol. 22: 263-269

Lavorel, J., Etienne, A. L. (1977). In vivo chlorophyll fluorescence. In: Barber, J. (ed.) Primary processes of photosynthesis. Elsevier Scientific Publications Co., Amsterdam, p. $203-268$

Legendre, L., Demers, S. (1984). Towards dynamic biological oceanography and limnology. Can. J. Fish. Aquat. Sci. 41: 2-19

Legendre, L., Legendre, P. (1983). Numerical ecology. Elsevier, Amsterdam

Lewis, M. R, Cullen, J. J., Platt, T (1984). Relationships between vertical mixing and photoadaptation of phytoplankton: similarity criteria. Mar. Ecol. Prog. Ser 15: $141-149$

Lewis, M. R., Smith, J. C. (1983). A small volume, shortincubation-time method for measurements of photosynthesis as a function of incident irradiance. Mar. Ecol. Prog. Ser. 13: 99-102

Lichtenthaler, H. K. (1981). Adaptation of leaves and chloroplasts to high quanta fluence rates. Photosynthesis VI. In: 
Akoynnoglon, G. (ed.) Photosynthesis and productivity, photosynthesis and environment. Balalon International Science Services, Philadelphia, p. 273-287

Loftus, M. E., Seliger, H. H. (1975). Some limitation of the in vivo fluorescence technique. Chesapeake Sci. 16: 79-92

Lorenzen, C. J. (1966). A method for the continuous measurements of in vivo chlorophyll concentration. Deep Sea Res. 13: $223-227$

Massol, R. H., Ballester, A. (1976). Nueva metodologia para la determinación en continuo de la actividad fotosintética de las algas fitoplanctonicas. Investigación pesq 40: 111-123 (in Spanish)

Mohanty, P., Govindjee (1974). The slow decline and the subsequent rise of chlorophyll fluorescence transients in intact algal cells. Plant Biochem. J. 1: 78-106

Neveux, J. (1982). Pigments du phytoplancton: composition et activité photochimique des chlorophylles et signification écologique de la fluorescence in vivo de la chlorophylle $\boldsymbol{a}$. Thèse de Doctorat d'Etat ès-sciences naturelles, Université Pierre et Marie Curie, Paris VI, p. 1-146

Neveux, J., Jupin, H. (1981). Une approche vers l'estimation de la production potentielle du phytoplancton par analyse des cinétiques d'induction de fluorescence. Mar. Biol. 63: 13-21 (in French, Abstract in English)

Papageorgiou, G. (1975). Chlorophyll fluorescence: an intrinsic probe of photosynthesis. In: Govindjee (ed.) Bioenergetics of photosynthesis. Academic Press, New York, p. 319-371

Platt, T., Gallegos, C. L., Harrison, W. G. (1980). Photoinhibition of photosynthesis in natural assemblages of marine phytoplankton. J. mar. Res. 38: 687-701

Platt, T., Harrison, W. G., Irwin, B., Howe, E. P., Gallegos, C. L. (1982). Photosynthesis and photoadaptation of marine phytoplankton in the arctic. Deep Sea Res. 29: 1159-1170

Prézelin, B. B. (1981). Light reactions in photosynthesis. In:
Platt, $T$ (ed.) Physiological bases of phytoplankton ecology. Can Bull. Fish. Aquat. Sci. 210: 1-43

Roy, S., Legendre, L. (1979). DCMU-enhanced fluorescence as an index of photosynthetic activity in phytoplankton. Mar Biol. 55: 93-101

Roy, S., Legendre, L. (1980). Field studies of DCMU-enhanced fluorescence as an index of in situ phytoplankton photosynthetic activity. Can. J. Fish. Aquat. Sci. 37: 1028-1031

Samuelsson, G., Oquist, G. (1977). A method for studying photosynthetic capacities of unicellular algae based on in vivo chlorophyll fluorescence. Physiol. Plant. 40: 315-319

Samuelsson, G., Oquist, G., Halldal, P. (1978). The variable chlorophyll a fluorescence as a measure of photosynthetic capacity in algae. Mitt. int. Verein. theor. angew. Limnol 21: $207-215$

Sweet, S. T., Guinasso, N. L. Jr. (1984). Effects of flow rate on fluorescence in vivo during continuous measurements in Gulf of Mexico surface water. Limnol. Oceanogr. 29: 397-401

Talling, J. F. (1957). The phytoplankton population as a compound photosynthetic system. New Phytol. 56: 133-149

Vincent, W. F. (1979). Mechanisms of rapid photosynthetic adaptation in natural phytoplankton communities. I. Redistribution of excitation energy between photosystems I and II. J. Phycol. 15: 429-434

Vincent, W F. (1980). Mechanisms of rapid photosynthetic adaptation in natural phytoplankton communities. II. Capacity for non-cyclic electron transport. J. Phycol. 16: 368-377

Yentsch, C. S., Lee, R. W. (1966). A study of photosynthetic light reactions and a new interpretation of sun and shade phytoplankton. J. mar. Res. 24: 319-337

Yentsch, C. S., Menzel, D. W. (1963). A method for the determination of phytoplankton chlorophyll and phaeophytin by fluorescence. Deep Sea Res. 10: 221-231

This paper was presented by Dr. T. Platt; it was accepted for printing on August 19, 1985 